\title{
REDUKSI SINAMALDOKSIM MENGGUNAKAN SISTEM KATALIS Zn/NH4CI
}

\author{
Ngadiwiyana $^{1}$, Ismiyarto ${ }^{1}$, Purbowatiningrum. R.S ${ }^{2}$.
}

1. Laboratorium Kimia Organik Jurusan Kimia Universitas Diponegoro 2.Laboratorium Biokimia Jurusan Kimia Universitas Diponegoro

\begin{abstract}
ABSTRAK
Sinamaldehid merupakan komponen utama minyak kayu manis (Cinnamomum) yang dapat diisolasi menggunakan pelarut natrium bisulfit. Pemanfaatan senyawa ini masih sangat terbatas, sehingga perlu dilakukan upaya pengubahan sinamaldehid menjadi senyawa turunannya yang lebih berdaya guna. Salah satunya, sinamaldehid dapat diubah menjadi senyawa amina melalui zat antara sinamaldoksim dengan reaksi reduksi. Senyawa amina tersebut digunakan sebagai bahan untuk mensintesis senyawa turunan antibiotik C-9154.

Reduksi sinamaldoksim menjadi senyawa amina dilakukan dengan cara reduksi hidrogenasi katalitik menggunakan katalis $\mathrm{Zn} / \mathrm{NH}_{4} \mathrm{Cl}$. Reaksi dilakukan dengan merefluks sinamaldoksim, $\mathrm{NH}_{4} \mathrm{Cl}_{(s)}$, dan serbuk $\mathrm{Zn}$ dengan pelarut metanol pada temperatur refluks $\left(58^{\circ} \mathrm{C}\right)$ selama $3 \mathrm{jam}$. Hasil disaring, selanjutnya filtrat hasil refluks dievaporasi. Hasil evaporasi diekstraksi dengan kloroform dan $\mathrm{NaCl}$ jenuh. Lapisan organik dievaporasi kembali. Hasil evaporasi dianalisis menggunakan instrumen FT-IR dan GC-MS.

Hasil reduksi sinamaldoksim berupa padatan gel berwarna coklat dengan dengan berat $0,43 \mathrm{~g}$ dan rendemen sebesar 64,35\%. Analisis hasil menggunakan spektrometer infra merah menunjukkan serapan gugus $C-N$ pada daerah 1330,8 $\mathrm{cm}^{-1}$. Serapan pada $3178 \mathrm{~cm}^{-1}$ menunjukkan serapan gugus $N$ $H$ dari senyawa amina. Hasil analisis GC-MS menunjukkan bahwa senyawa amina yang diperoleh dari reduksi sinamaldoksim berupa sinamilamin yang merupakan senyawa amina primer $\left(t_{R}=16,431\right.$ menit dengan kelimpahan 0,58\%), ( $N$-metil-3-fenil)-2-propenamin yang merupakan senyawa amina sekunder $\left(t_{R}=20,258\right.$ menit dengan kelimpahan 0,79\%) dan ( $N, N$ - dimetil-3-fenil)-2-propenamin yang merupakan senyawa amina tersier $\left(t_{R}=26,666\right.$ menit dengan kelimpahan $14,79 \%$ ).
\end{abstract}

Kata kunci: Minyak Kayu Manis, Sinamaldoksim dan Reduksi

Cinnamaldehyde is the major compound of cinnamomum oil that can be isolated using sodium bisulphite solvent. The used of this compound is still restricted, therefore cinamaldehide need to be changed to its more useful derivates. Cinnamaldehyde can be trnsformated to corresponding amine compounds via cinnamaldoxime by reduction reaction. The amine compounds are used as substance to synthesis of antibiotic C-9154 derivates.

Reduction of cinnamaldoxime to amine compounds were carried out with reduction of catalytic hydrogenation method using $\mathrm{Zn} / \mathrm{NH}_{4} \mathrm{Cl}$. The reaction was carried out with refluxing of cinnamaldoxime, $\mathrm{NH}_{4} \mathrm{Cl}_{(s)}$, zinc dust, and methanol as solvent at reflux temperature $\left(58^{\circ} \mathrm{C}\right)$ for 3 hours. After filtration the result, filtrate was evaporated. The residue was extracted using chloroform and saturated $\mathrm{NaCl}$. The organic layer was evaporated again and was analyzed using FT-IR and GC-MS.

The product of cinnamaldoxime reduction is a soft brown solid gel with mass of $0,34 \mathrm{~g}$ and rendemen of 64,35\%. Analysis by FT-IR instrument showed absorbance of $C-N$ group at 1330,8 $\mathrm{cm}^{-1}$. Absorption at $3178 \mathrm{~cm}^{-1}$ showed of N-H group from amine compounds. Analysis GC-MS showed that the product of cinamaldoxime reduction is cinnamilamin as primary amine $\left(t_{R}=16,431\right.$ minute with $0,58 \%$ abundance), ( $N$-methyl-3-phenyl)-2-propenamine as secondary amine $\left(t_{R}=20,258\right.$ minute with $0,79 \%$ abundance), and ( $N, N$-dimethyl-3-phenyl)-2-propenamine as tertier amine $\left(t_{R}=26,666\right.$ minute with 14,79\% abundance). MS data showed moleculer ion $\mathrm{m} / \mathrm{e}=132$ and base peak $\mathrm{m} / \mathrm{e}=91$ for cinnamilamine, fragmentation with moleculer ion and base peak m/e $=146$ for $(\mathrm{N}$-methyl-3-phenyl)-2propenamine, and moleculer ion $\mathrm{m} / \mathrm{e}=160$ and base peak $\mathrm{m} / \mathrm{e}=117$ for $(\mathrm{N}, \mathrm{N}$-dimethyl-3-phenyl)-2propenamine. Based on FT-IR and GC-MS data, the result of cinnamaldoxime reduction from this research are cinnamilamine (0,58\% abundance), ( $N$-methyl-3-phenyl)-2-propenamine $(0,79 \%)$, and ( $N, N$-dimethyl-3-phenyl)-2-propenamine (14,79\% abundance).

Keywords: Cinnamomum oil, Cinnamaldehyde and Reduction 


\section{PENDAHULUAN}

Kayu manis atau Cinnamon termasuk dalam anggota genus Cinnamomum dari famili Lauraceae. Beberapa spesies kayu manis yang penting dalam perdagangan dunia adalah $C$. cassia, C. Zeylanicum, C. Camphora (Jayaprakasha et al, 2002). Pemanfaatan kayu manis masih sangat terbatas, misalnya sebagai salah satu ramuan dalam bahan flavoring yang banyak digunakan dalam industri makanan. Pemanfaatan lain dari kayu manis adalah dengan diambil minyaknya melalui distilasi uap (Guenther, 1990).

Kandungan utama minyak kayu manis adalah sinamaldehid $75 \%$ (Senayake et al, 1978). Sinamaldehid dapat diisolasi dari minyak kayu manis dengan menggunakan pelarut $\mathrm{NaHSO}_{3}$ (natrium bisulfit) (Mallavarapu et al, 1995). Berdasarkan struktur kimianya, sinamaldehid mempunyai cincin benzen, gugus alkena dan gugus aldehid, sehingga memungkinkan untuk diubah menjadi gugus fungsi lain. Ngadiwiyana $d k k$ (2004) melakukan pemanjangan sistem terkonjugasi sinamaldehid yang digunakan sebagai bahan aktif tabir surya. Sinamaldehid dapat juga dioksidasi menjadi asam sinamat yang selanjutnya diesterkan menjadi etil atau metil sinamat yang dapat digunakan sebagai bahan kosmetik, akan tetapi kurang potensial karena sifatnya yang sensitif terhadap kulit (Jayaprakasha et al, 2002).

Gugus aldehid pada sinamaldehid dapat diubah menjadi amina melalui senyawa antara oksim. Abiraj (2004) berpendapat bahwa perubahan senyawa karbonil menjadi amina melalui pembentukan oksim adalah suatu transformasi gugus fungsi yang bermanfaat dalam sintesis organik. Jalur ini melalui beberapa tahap reaksi, pertama sinamaldehid diubah menjadi senyawa oksim melalui reaksi kondensasi dengan hidroksilamin (Wikipedia, 2005), selanjutnya oksim direduksi menjadi senyawa amina (Abiraj, 2003).

Reduksi oksim menjadi amina dapat dilakukan dengan beberapa metode menggunakan reduktor $\mathrm{LiAlH}_{4}$ dan $\mathrm{NaBH}_{4}$, tetapi kedua pereaksi ini dapat bereaksi dengan cepat pada keadaan lembab atau uap air sehingga sukar menggunakan senyawa ini dalam keadaan murni (Sastrohamidjojo, 2001), di samping mempunyai keterbatasan dalam kemoselektivitas (Abiraj, 2004). Metode reduksi yang lebih efektif untuk mereduksi komponen organik adalah dengan metode hidrogenasi menggunakan katalis heterogen. Hal ini karena kondisi reaksinya yang aman, mudah dilakukan, dan mempunyai daya selektivitas yang tinggi. Hidrogenasi katalitik oksim menjadi amina telah dilakukan menggunakan $\mathrm{HCOONH}_{4}$ dan $10 \%$ (b/b) Pd/C, sikloheksana dan $10 \%$ (b/b) Pd/C, tetapi sistem tersebut reaksinya memerlukan waktu yang lama sekitar 10 jam, harga katalis yang mahal, dan menghasilkan produk dengan rendemen yang kecil (Abiraj, 2003).

Abiraj (2003) telah melakukan reduksi senyawa benzaldoksim menggunakan $\mathrm{Zn} / \mathrm{HCOONH}_{\mathrm{a}}$ dalam pelarut metanol yang menghasilkan senyawa benzilamin dengan rendemen tinggi sekitar $92 \%$. Menggunakan acuan jurnal penelitian tersebut, pada penelitian ini akan dilakukan reduksi sinamaldoksim dari sinamaldehid menggunakan metode hidrogenasi katalitik dengan sistem katalis $\mathrm{Zn} / \mathrm{NH}_{4} \mathrm{Cl}$. Seperti halnya $\mathrm{HCOONH}_{4}, \mathrm{NH}_{4} \mathrm{Cl}$ dapat terurai 
dalam pelarut metanol menghasilkan ion $\mathrm{NH}_{4}{ }^{+}$ sebagai sumber $\mathrm{H}^{+}$yang dapat digunakan dalam proses hidrogenasi. Oleh karena itu, $\mathrm{NH}_{4} \mathrm{Cl}$ digunakan menggantikan $\mathrm{HCOONH}_{4}$. Selain itu, $\mathrm{NH}_{4} \mathrm{Cl}$ dipilih karena senyawa ini lebih mudah didapat dan harganya lebih murah dibandingkan dengan $\mathrm{HCOONH}_{4}$.

Senyawa amina hasil reduksi sinamaldoksim ini, selanjutnya diharapkan dapat digunakan sebagai bahan untuk sintesis turunan antibiotik C-9154 yang memiliki khasiat antimikroba.

\section{METODOLOGI}

Reduksi senyawa sinamaldoksim dilakukan dengan mereaksikan sinamaldoksim $5 \mathrm{mmol}$ dalam metanol $(30 \mathrm{ml})$ dengan larutan amonium klorida 20 mmol dan serbuk seng 10 mmol. Rasio mol antara senyawa sinamaldoksim dan amonium klorida yang digunakan adalah 1: 4. Campuran diaduk dengan stirrer pada saat refluks selama 3 jam. Setelah reaksi selesai, campuran hasil reaksi disaring menggunakan kertas saring. Filtrat dievaporasi dalam vakum. Residu hasil evaporasi ditambah larutan $\mathrm{NaCl}$ jenuh untuk mengambil kelebihan amonium klorida, kemudian diekstraksi dua kali dengan kloroform. $\mathrm{Na}_{2} \mathrm{SO}_{4}$ anhidrat ditambahkan dalam lapisan kloroform untuk mengikat molekul air dan selanjutnya disaring. Filtrat yang diperoleh dievaporasi dalam evaporator vakum. Analisis menggunakan FT-IR dan GC-MS dilakukan untuk menentukan gugus fungsi dan berat molekul dari senyawa yang dihasilkan.

\section{HASIL DAN PEMBAHASAN}

Proses reduksi sinamaldoksim ini diawali dengan melarutkan sinamaldoksim dalam metanol kemudian dicampur dengan ammonium klorida dan serbuk seng. Pada tahap awal terjadi reaksi antara amonium klorida $\left(\mathrm{NH}_{4} \mathrm{Cl}\right)$ dan seng (Zn) menghasilkan $\mathrm{ZnCl}_{2}$, gas amoniak, ion hidrogen dan elektron. Garam $\mathrm{ZnCl}_{2}$ dapat diketahui dengan adanya endapan berwarna abuabu dan adanya gas $\mathrm{NH}_{3}$ ditandai dengan timbulnya gelembung-gelembung gas (busa) berwarna putih. Reaksinya adalah sebagai berikut:

$4 \mathrm{NH}_{4} \mathrm{Cl}+2 \mathrm{Zn} \longrightarrow 2 \mathrm{ZnCl}_{2}+4 \mathrm{NH}_{3}+4 \mathrm{H}^{+}+4 \mathrm{e}$ Ion hidrogen dan elektron yang dihasilkan dapat digunakan dalam reduksi sinamaldoksim.. Reaksi adisi hidrogen pada sinamaldoksim ini dikatalisis oleh $\mathrm{ZnCl}_{2}$, agar reaksi dapat berjalan dengan lancar (Fessenden, 1997). Mekanisme reaksi selengkapnya adalah sebagai berikut: 


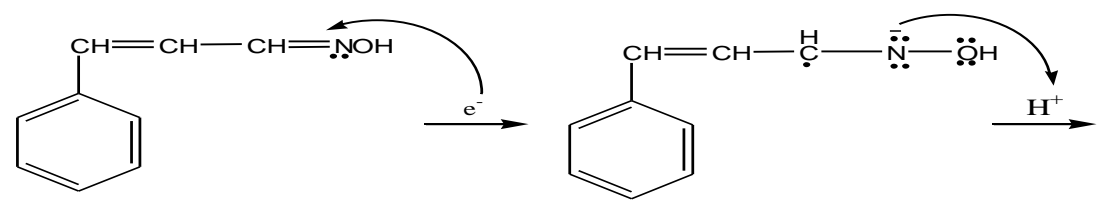

sinamaldoksim
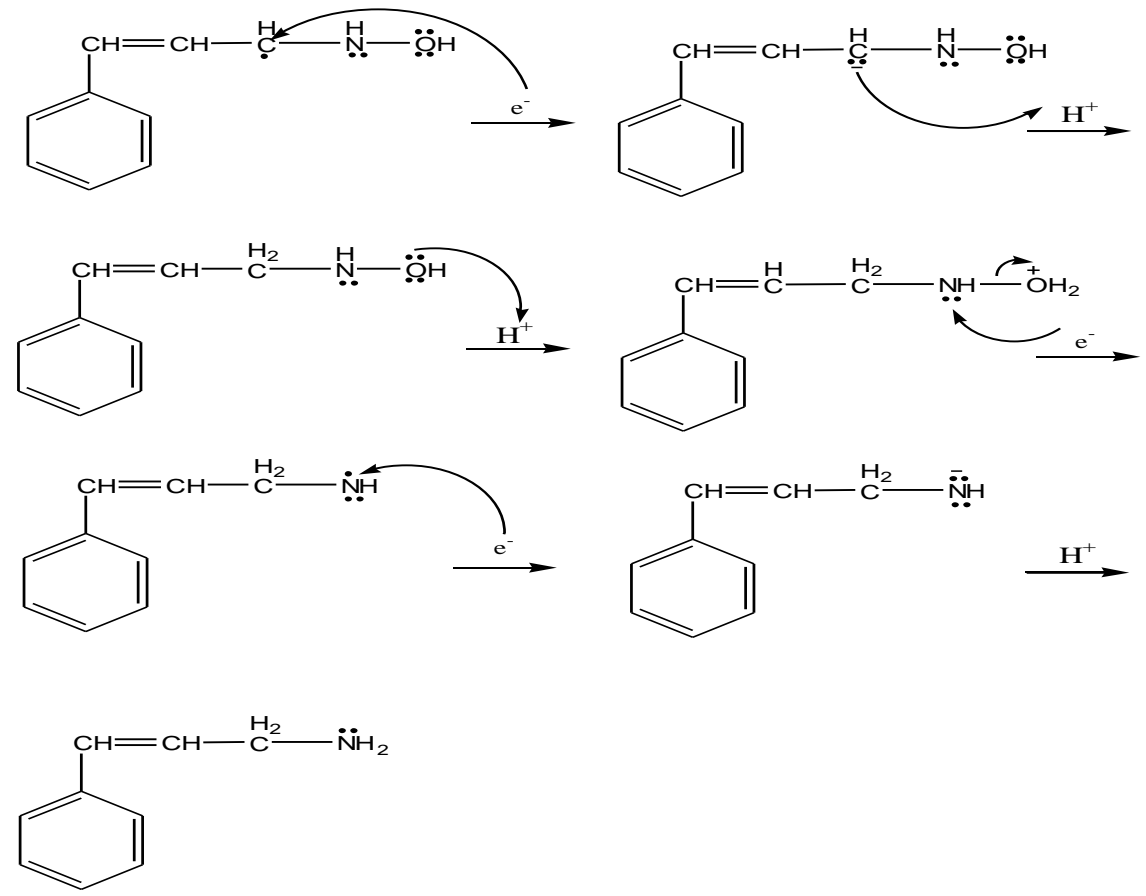

sinamilamin

Meskipun reaksi hidrogenasi bersifat eksoterm, tetapi reaksi tidak berjalan secara spontan karena energi pengaktifan sangat tinggi (Fessenden, 1997), oleh karena itu reaksi reduksi sinamaldoksim ini berlangsung dalam kondisi refluks dengan temperatur $58^{\circ} \mathrm{C}$ selama 3 jam. Hasil analisis menggunakan instrumen FT-IR untuk senyawa hasil reduksi sinamaldoksim ditunjukkan dalam gambar berikut:

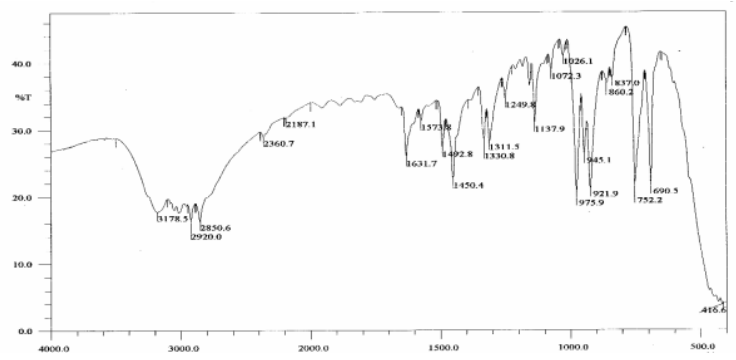

Gambar 1. Spektrum Infra Merah Senyawa Hasil Reduksi Sinamaldoksim
Bila spektrum tersebut dibandingkan dengan spektrum FT-IR senyawa sinamaldoksim diperoleh beberapa perbedaan. Dari perbedaan tersebut dapat dilihat bahwa pada spektrum FTIR senyawa hasil reduksi sinamaldoksim muncul serapan gugus $\mathrm{C}-\mathrm{N}$ amina pada serapan pada $1330,8 \mathrm{~cm}^{-1}$. Gugus N-H untuk amina primer ditunjukkan oleh serapan pada $3178 \mathrm{~cm}^{-1}$. Serapan 2920,0 $\mathrm{cm}^{-1}$ menunjukkan gugus C-H $\mathrm{sp}^{3}$. Daerah serapan 1450,4 $\mathrm{cm}^{-1}$ menunjukkan adanya cincin aromatis. Serapan pada bilangan gelombang $1631.7 \mathrm{~cm}^{-1}$ menunjukkan gugus $\mathrm{C}=\mathrm{N}$ dari senyawa sinamaldoksim. Hal ini menjelaskan bahwa sinamaldoksim masih ada dalam senyawa hasil reduksi. Dengan demikian, serapan $3178 \mathrm{~cm}^{-1}$ merupakan overlaping antara gugus $\mathrm{C}-\mathrm{N}$ dari amina primer dan gugus $\mathrm{O}-\mathrm{H}$ dari sinamaldoksim. 
Hasil analisis produk dengan GC-MS disajikan pada gambar berikut:

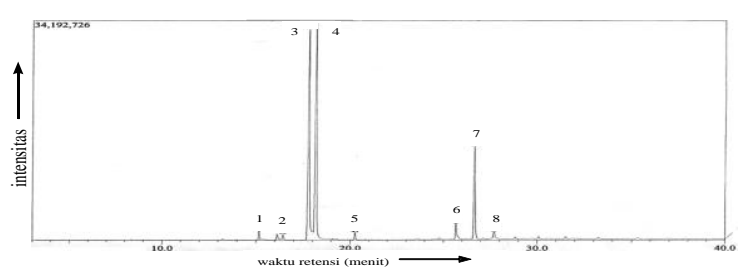

Senyawa-senyawa yang terdapat dalam hasil reduksi senyawa sinamaldoksim dirangkum dalam tabel dibawah ini:

Gambar 2. Kromatogram Hasil Reduksi

Senyawa Sinamaldoksim

Tabel 1. Data Hasil Analisis GC-MS Senyawa Hasil Reduksi Sinamaldoksim

\begin{tabular}{|c|c|c|c|c|c|c|}
\hline No & Puncak & $\begin{array}{l}\text { Waktu } \\
\text { Retensi } \\
\text { (menit) }\end{array}$ & $\begin{array}{c}\text { Kelimpahan } \\
(\%)\end{array}$ & $\begin{array}{c}\text { Massa Molekul } \\
\left(\text { g.mol }^{-1}\right)\end{array}$ & $\mathbf{m} / \mathbf{e}$ & Senyawa \\
\hline 1 & 2 & 16,431 & 0,58 & 133 & $\begin{array}{l}132,117,104,91 \text { (puncak dasar), } \\
77,65,51,39\end{array}$ & sinamilamin \\
\hline 2 & 3 & 17,802 & 39,14 & 147 & $\begin{array}{l}146,130 \text { (puncak dasar), 115, 103, } \\
91,77,63,51,39\end{array}$ & Sin-sinamaldoksim \\
\hline 3 & 4 & 18,175 & 40,43 & 147 & $\begin{array}{l}146,130 \text { (puncak dasar), 115, 103, } \\
91,77,63,51,39\end{array}$ & Anti-sinamaldoksim \\
\hline 4 & 5 & 20,258 & 0,79 & 147 & $\begin{array}{l}146 \text { (puncak dasar), 131, 118, 103, } \\
91,77,63,51,39\end{array}$ & $\begin{array}{l}(N \text {-metil-3-fenil)-2- } \\
\text { propenamin }\end{array}$ \\
\hline 5 & 7 & 26,666 & 14,79 & 161 & $\begin{array}{l}251,160,146,132,117 \text { (puncak } \\
\text { dasar), 104, 91, 77, 56, 44, } 39\end{array}$ & $\begin{array}{l}N, N \text {-dimetil-3-fenil)-2- } \\
\text { propenamin }\end{array}$ \\
\hline
\end{tabular}

Puncak 3 dan 4 dengan $t_{R}=17,802$ menit dan $t_{R}$ $=18,175$ menit dengan kelimpahan berturutturut adalah 39,14\% dan 40,34\% menunjukkan masih adanya senyawa sinamaldoksim. Hal ini didukung oleh data spektra FT-IR dengan adanya serapan daerah $1631.7 \mathrm{~cm}^{-1}$ yang menunjukkan gugus $\mathrm{C}=\mathrm{N}$ dari senyawa sinamaldoksim. Keberadaan sinamaldoksim dalam hasil reduksi ini disebabkan karena kondisi reaksi belum optimal.

\section{KESIMPULAN}

Sinamaldoksim dapat direduksi menjadi senyawa amina menggunakan metode reduksi hidrogenasi katalitik dengan sistem katalis $\mathrm{Zn} / \mathrm{NH}_{4} \mathrm{Cl}$. Hasil reduksi sinamaldoksim berupa padatan gel berwarna coklat dengan berat $0,43 \mathrm{~g}$ dan rendemen sebesar 64,35\%. Berdasarkan analisis menggunakan FT-IR dan GC-MS, hasil reduksi sinamaldoksim dari penelitian ini adalah senyawa sinamilamin (kelimpahan 0,58\%), senyawa (N-metil-3-fenil)-2-propenamin (kelimpahan $0,79 \%)$, dan senyawa $(N, N-$ dimetil-3-fenil)-2-propenamin (kelimpahan $14,79 \%)$.

\section{DAFTAR PUSTAKA}

Abiraj, K., and Gowda D.C., 2003, "Zinc/Ammonium Formate: A New Facile System for the Rapid and Selective reduction of Oxime to Amines", J. Chem. Res. (s) 6, 332-334.

Abiraj.K and Gowda D.C., 2004, "MagnesiumCatalyzed reduction of Oxime to Amines 
using Ammonium Formate", Synthetic Communications 34(4), 599-605.

Entwistle, I.D., Johnstone, R.A.W., and Wilby, A.H., 1985, "Heterogeneous Catalytic Transfer Hydrogenation and Its Relation to Other Methods for Reduction of Organic Compouns", Chem. Rev, American Chemical Society, pp. 131-149.

Fessenden, J.R., dan Fessenden, J.S., 1990, "Kimia Organik" (terjemahan Pudjaatmaka, A.H.), Jilid 2, Edisi ketiga, Erlangga: Jakarta, hal. 34, 223, dan 454457.

Fessenden, J.R., dan Fessenden, J.S., 1997, "Kimia Organik" (terjemahan Pudjaatmaka, A.H.), Jilid I, Edisi keempat, Erlangga: Jakarta, hal. 409-413.

Guenther, E., 1990, "The Essential Oils" (terjemahan Ketaren, S.), "Minyak Atsiri", jilid II, Penerbit Universitas Indonesia: Jakarta.

Griffin, R.W., 1969, "Modern Organik Chemistry", International Student Edition, Mc Graw-Hill Kogakusha Ltd:Tokyo.

Jayaprakasha, G.K., Rao, L.J., and Sakariah, K.K., 2002, "Chemical Composition of tha Volatile Oil from the Fruits of
Cinnamomum zeylanicum Blume". Flav. Frag. J; pp. 990-993.

Mallavarapu, G.R., Ramesh, S., Chandrasekhara, R.S., Rajeswara Rao, B.R., Kaul, P.N., and Battacharya, A.K., 1995, "Investigation of the Essential Oil of Cinnamon Leaf Grown at Bangalore and Hyderabad", Flav. Frag. J. 1995. 10; pp. 239-242.

Ngadiwiyana, Ismiyarto, dan Anam, K., 2004, "Pemanjangan Sistem Terkonjugasi Sinamaldehid dan Uji Aktivitas sebagai Bahan Tabir Surya", Jurnal Kimia Sains dan Aplikasi vol VIII, No. I hal. 24-29.

Sastrohamidjojo, H., dan Pranowo D.H., 2001, "Sintesis Senyawa Organik", FMIPA Universitas Gadjah Mada: Yogyakarta.

Senayake, U.M., Lee, T.H., and Wills, R.B.H., 1978, "Volatile Constituents of Cinnamon (Cinnamomum Zeylanicum) Oils. $J$. Agric. Food Chem., 1978. 26. pp. 822824.

Silverstein, R.M., Bassler, G.C., dan Morril, T.C., 1986, "Penyidikan Spektrometrik Senyawa Organik", edisi keempat, Erlangga: Jakarta.

Wikipedia, 2005, "Oxime, From Wikipedia, the free encyclopedia". 